\title{
EXPERIÊNCIA TURÍSTICA \\ MEMORÁVEL,PERCEPÇÃO \\ COGNITIVA, REPUTAÇÃO E \\ LEALDADE AO DESTINO: UM \\ MODELO EMPÍRICO
}

MEMORABLE TOURIST EXPERIENCE, COGNITIVE PERCEPTION, REPUTATION AND LOYALTY TO THE DESTINATION: AN EMPIRICAL MODEL

EXPERIENCIA TURÍSTICA MEMORABLE, PERCEPCIÓN COGNITIVA, REPUTACIÓN Y LEALTAD AL DESTINO: UN MODELO EMPÍRICO

Tiago Aroeira

Universidade Federal de Minas Gerais

Doutorando em Marketing e Estratégia, pela Universidade Federal de Minas Gerais

Belo Horizonte, Minas Gerais, Brasil

tiagoaroeira@gmail.com

\section{Ana Carmem Dantas}

Universidade Federal de Minas Gerais

Especialista em Gestão de Negócios, pela Universidade Federal de Minas Gerais

Belo Horizonte, Minas Gerais, Brasil

apinhotavares@gmail.com

\section{Marlusa de Sevilha Gosling}

Universidade Federal de Minas Gerais

Professora no Centro de Pós-Graduação em Administração da Universidade

Federal de Minas Gerais

Pós-Doutora em Gestão do Turismo pela Universidade do Algarve, Portugal

Belo Horizonte, Minas Gerais, Brasil

marlusa@ufmg.br 
RESUMO: Os destinos, de acordo com mudanças de comportamento dos turistas, começam a se posicionar como fornecedores de experiências. Neste contexto, estudos recentes apontam que as experiências turísticas relevantes tendem a aumentar a propensão dos turistas de se lembrarem do destino. O objetivo principal deste estudo foi propor e testar um modelo de relações entre as dimensões subjacentes da Experiência Turística Memorável, da Percepção Cognitiva, da Reputação e da Lealdade ao Destino. A metodologia foi um survey com 664 respondentes de todos os estados do Brasil. Realizaram-se (1) a análise e exclusão de outliers univariados e multivariados, (2) a análise fatorial exploratória e (3) a validação do modelo de mensuração e do modelo de estrutura usando modelagem por equações estruturais. Os resultados indicam que 11 das 13 hipóteses testadas são significativas ao nível de $1 \%$. Além disso, observaram-se as cinco dimensões subjacentes na Experiência Turística Memorável - (1) Hedonismo, (2) Novidade, ( 3 ) Conhecimento e Cultura Local, (4) Renovação e (5) Envolvimento. A Novidade foi a dimensão mais saliente.

PALAVRAS-CHAVE: Experiência Turística Memorável, Reputação do Destino, Leadade.

ABSTRACT: As tourists' behavior changes, tourism destinations have started to assume the role of experience providers. In this context, recent studies reveal that relevant tourist experiences tend to increase the likelihood that the tourist will remember the destination. The main purpose of this paper was to propose and test a model of relations between the underlying dimensions of memorable tourism experience, cognitive perception, reputation, and loyalty towards a destination. The study method consisted of a survey involving 664 tourists from all Brazilian states. The study procedures included (1) analysis and exclusion of univariate and multivariate outliers, (2) exploratory factor analysis, and (3) validation of the measurement model and structural model using structural equation modeling. The results indicate that 11 of the 13 tested hypotheses were validated at a significance level of $1 \%$. It was also observed that among the five underlying dimensions of Memorable Touristic Experience identified - (1) Hedonism, (2) Novelty, (3) Local Knowledge and Culture, (4) Revival and (5) Engagement - Novelty was the one that stood out most.

KEYWORDS: Memorable Touristic Experience, Reputation of Destination, Loyalty.

RESUMEN: Los destinos, de acuerdo con los cambios de comportamiento de los turistas, empiezan a posicionarse como proveedores de experiencias. En este contexto, estudios recientes señalan que las experiencias turísticas relevantes tienden a aumentar la propensión de los turistas a recordar el destino. El objetivo principal de este estudio fue proponer y testear un modelo de relaciones entre las dimensiones subyacentes de la Experiencia Turística Memorable, de la Percepción Cognitiva, de la Reputación y de la Lealtad al Destino. La metodología fue un survey con 664 encuestados de todos los estados de Brasil. Se realizaron (1) el análisis yexclusión de outliers univariados y multivariados, (2) el análisis factorial exploratorio y (3) la validación del modelo de mensuración y del modelo de estructura usando el modelado por ecuaciones estructurales. Los resultadosindican que 11 de las 13 hipótesis testeadas son significativas a nivel del $1 \%$. Además, se observaron las cinco dimensiones subyacentes en la Experiencia Turística Memorable - (1) Hedonismo, (2) Novedad, (3) Conocimiento y Cultura Local, (4) Renovación y (5) Envolvimiento. La Novedad fue la dimensión más destacada.

PALABRAS CLAVE: Experiencia Turística Memorable; Reputación del Destino; Lealtad. 
relevância do turismo como atividade socioeconômica pode
ser amplamente percebida por números apresentados pela
Organização Mundial do Turismo-OMT (2014). Segundo a OMT, o turismo gera um de cada onze empregos formais no mundo e é responsável por 9\% do PIB mundial a partir de sua influência direta e indireta. No Brasil, segundo o Ministério do Turismo (2012), 115 mil foi o número de empregos gerados pelas 80 maiores empresas do setor turístico, as quais faturaram $\mathrm{R} \$$ 57,6 bilhões. Os dados do Ministério do Turismo do Brasil evidenciam que houve um aumento nas intenções de viagens nos turistas brasileiros, que no ano de 2012 apresentava 1,5\% a menos que em 2013.

Segundo Oliani, Rossi e Gervasoni (2011), o turismo é uma atividade econômica composta por diversos fatores que o caracterizam, como: localização geográfica, recursos naturais, clima, infraestrutura turística, recursos paisagísticos, história, desenvolvimento econômico, políticas públicas e estabilidade política. O destino turístico pode ser compreendido como um local determinado que atrai turistas para uma visita temporária e pode ser desde continentes, países, cidades e vilas até uma área mais restrita construída somente para isso (Pike, 2004), como um resort, por exemplo.

A fim de se incentivar a visitação a determinado destino e assim elevar a atratividade turística, Oh, Fiore e Jeoung (2007) argumentam que as organizações do destino turístico devem compreender que o interesse do turista vai além de somente visitar o local, pois ele pretende vivenciar significativas experiências turísticas.

Quanto ao conceito de experiência, Pine e Gilmore (1998) indicam que a evolução do foco na oferta de serviços para a atenção voltada a proporcionar experiências ao consumidor é caracterizada como a economia da experiência. Neste contexto, o consumidor apresenta-se disposto a pagar mais por sensações positivas do que por produtos e serviços que sejam capazes de cumprir apenas a função a qual se propõem (Schmitt, 2002). 
A recordação da experiência turística pelo turista é algo significativo a partir da observação de que a memória possui influência positiva sobre a intenção comportamental do consumidor (Wirtz, Kruger, Scollon, \& Diener, 2003). Diante disso, começam a emergir estudos que objetivam desenvolver escalas capazes de mensurar mais do que a experiência turística, mas a experiência turística memorável (MTE). Os estudos de MTE ainda se apresentam incipientes e a escala mais relevante de mensuração deste construto foi desenvolvida por Kim, Ritchie e McCormick (2010).

Em complemento, Chen e Dubinsky (2003) afirmam que a reputação ao destino desempenha um papel relevante na indústria do turismo, pois uma reputação favorável a um destino desperta a credibilidade dos turistas perante aquele local. A reputação é definida no âmbito dos estudos turísticos como uma síntese de opiniões, percepções, conhecimentos e atitudes dos diferentes participantes daquele local, sejam eles turistas ou residentes da comunidade local (Christou, 2003).

Baloglu e McCleary (1999) definem a percepção cognitiva como a forma em que a pessoa consegue perceber os atributos do destino turístico. São atribuídas como as principais funções do sistema cognitivo: ações de interpretar, perceber o sentido e compreender tudo aquilo que julga como aspectos significativos das experiências pessoais (Peter, \& Olson, 2006). Em complemento, Artigas, Vilches-Montero e Yrigoyen (2015) destacam que os destinos turísticos buscam alcançar as percepções cognitivas favoráveis.

Adicionalmente, a lealdade ao destino é algo importante, pois tem influência significativa no sucesso do destino, sendo composta pela junção da intenção de retorno dos turistas e da recomendação ao destino turístico (Kozak, Bigné, Andreu, \& Others, 2004). A partir da relevância socioeconômica do turismo como atividade econômica, diante da importância dos temas experiência turística memorável, reputação, percepção cognitiva e lealdade ao destino para estudos acadêmicos sobre turismo, este estudo se propõe a responder ao seguinte problema de pesquisa: "Quais são as relações significativas entre a experiência turística memorável, a percepção cognitiva, a reputação e a lealdade ao destino na percepção de turistas brasileiros?". 
E subsidiariamente, mensurar a relação entre as dimensões subjacentes da experiência turística memorável, percepção cognitiva, reputação e lealdade ao destino junto aos turistas brasileiros.

\section{ECONOMIA DA EXPERIÊNCIA E O MARKETING DE EXPERIÊNCIA}

Até meados dos anos 1980 o consumidor era prioritariamente compreendido pelos estudiosos como alguém orientado à tomada de decisões lógicas guiadas estritamente pela racionalidade. Neste contexto, Holbrook e Hirschman (1982) argumentaram sobre a importância dos estudos de marketing se concentrarem na compreensão aprofundada dos aspectos emocionais que influenciam as decisões de consumo dos consumidores. No entanto, o tema da experiência passou a ter maior relevância de fato para os estudos de marketing a partir do final da década de 1990, pelo impacto proporcionado pela publicação de Pine e Gilmore (1998) sobre a nova economia da experiência como uma evolução da economia de serviços.

Pine e Gilmore (1998) argumentam que a economia mudou muito ao longo dos tempos e, atualmente, o contexto propicia a emersão da economia da experiência. Os autores reforçam que proporcionar experiências aos consumidores de acordo com a subjetividade e com a individualidade que possuem apresenta-se como algo de extrema relevância para as organizações. Os autores argumentam que a questão central não está relacionada à decisão da empresa de apresentar ou não ao mercado uma oferta de experiência, mas sim "quando" a empresa apresentará esta oferta de experiência aos seus consumidores.

A economia da experiência baseia-se essencialmente na observação de que os consumidores buscam uma experiência única de algo mais relevante do que o mero consumo racional de produtos e serviços adicionais (Pine, \& Gilmore, 1999). Esta situação conduz os produtores a oferecerem valor agregado por meio de ofertas adicionais e mais relevantes (Jensen, 1999; Tarssanen, \& Kylanen, 2007). Em complemento, observa-se que o valor 
agregado apresenta benefícios tanto para a experiência do consumidor quanto para o lucro do produtor (Mehmetoglu, \& Engen, 2011).

Paradesenvolverofertasqueproporcionemexperiênciasaosconsumidores, Lipovetsky e Machado (2007) argumentam que é preciso oferecer experiência viva, o inesperado e o extraordinário capazes de causar emoção, ligação, afetos e sensações. Em concordância, Schmitt (2002) argumenta que a experiência pode ser ofertada de forma abrangente, dinâmica e diversificada, em que se considera a relevância dos consumidores se apresentarem como pessoas influenciadas por aspectos racionais e lógicos, bem como por aspectos emocionais para as decisões de consumo a serem tomadas. $\mathrm{O}$ autor propõe que as experiências sejam construídas de formas distintas, como: (a) experiências sensoriais (sensação); (b) experiências afetivas (sentimentos); (c) experiências cognitivas (pensamento); (d) experiências físicas de comportamento e estilo de vida (ação); e (e) experiências de identidades sociais que resultam do relato de uma referência de grupo ou identificação cultural. Observa-se que Schmitt(2002) propõe cinco tipos de experiência a serem proporcionadas pelas empresas a fim de envolver 0 consumidor de forma significativa.

\section{CONCEITO DE EXPERIÊNCIA APLICADO AO TURISMO}

O turismo pode ser caracterizado como um tipo de prestação de serviço (Beni, 2002; Tonini, 2009). Beni (2002) afirma que o consumo do turismo é algo predominantemente intangível, em que o serviço é consumido pelo turista ao mesmo tempo que é produzido pelos prestadores de serviço. Diante destas peculiaridades, Tonini (2009) afirma que as sensações proporcionadas aos turistas no momento em que consomem o serviço turístico podem ser incentivadas para que se agregue valor ao consumidor e, assim, seja possível elevar o fluxo turístico no destino. Em complemento, Oh et al. (2007) argumentam que o interesse de visitar determinado destino turístico está mais diretamente relacionado ao objetivo do turista de vivenciar experiências adequadas às suas expectativas do que efetivamente o interesse restrito às características físicas do destino. 
Diante disso, Beni (2003) argumenta que a capacidade de proporcionar experiências turísticas relevantes ao turista será, cada vez mais, uma condição de sobrevivência para as organizações deste segmento. De acordo com esta abordagem, Richards e Others (2001) sinalizam que diversos destinos turísticos começam a se posicionar como provedores de experiências. Oh et al. (2007) afirmam que esta evolução é necessária pois os turistas objetivam obter experiências envolventes atreladas aos bens e serviços consumidos no destino.

A partir do objetivo de potencializar as experiências turísticas proporcionadas, Ooi (2005) ressalta a importância de se considerar que os turistas que visitam um mesmo destino possuem diferentes interesses, histórico cultural, origem, entre outros fatores que os conduzem a possuir intepretações singulares diante de cada destino turístico visitado. Diante disso, concordam e explicam, por exemplo, que as pessoas habitualmente viajam por quatro razões distintas: (i) físicas - viajam com o objetivo de um descanso físico, para uma competição esportiva, recreação, por recomendação médica, etc.; (ii) culturais - viajam para realizar o desejo de conhecer um local, seus costumes, as artes e o folclore existente ali; (iii) interpessoais - viajam para que possam encontrar pessoas, visitar amigos ou até mesmo fazer novas amizades; (iv) de status e prestígio - viajam pela busca do reconhecimento, pela atenção recebida, conhecimento e para gerar uma boa reputação.

Diante disso, Pine e Gilmore (1999) argumentam que a experiência se caracteriza-por ocorrer a partir da interação do consumidor (neste caso o turista) com a situação na qual está inserido. Assim, observa-se que os aspectos subjetivos inerentes ao turista e ao contexto ao qual está inserido influenciarão sua percepção diante da experiência vivenciada.

Em complemento, Oh et al. (2007) acrescentam que as consequências adquiridas por meio das experiências turísticas são pouco exploradas, recebendo menos atenção e aprofundamento do que os antecedentes que são amplamente investigados e discutidos. Os autores complementam ainda que isto acontece mesmo existindo a evidência de que alguns resultados 
da experiência turística, como recreção mental ou espiritual, bem-estar e realização, geram benefícios a longo prazo.

Pine e Gilmore (1999) relatam que uma experiência bem executada conduz a uma memória de boa qualidade, ou seja, as lembranças serão capazes de gerar no turista uma atitude positiva com relação ao destino. Oh et al. (2007) acrescentam que as memórias podem ser muito fortes quando a experiência turística for negativa. Os autores acrescentam que a decepção gerada no turista pode ser uma consequência de falhas no serviço ou na entrega de produtos, as quais podem gerar nele atitudes negativas perante o destino.

Quanto à indicação das dimensões subjacentes às experiências turísticas, Kim et al. (2010) realizaram um extenso levantamento bibliográfico, no qual indicam que as principais dimensões identificadas e propostas por estudiosos do conceito de experiência em turismo são: envolvimento, hedonismo, felicidade, prazer, relaxamento, estímulo, repouso, interação social, espontaneidade, significância, conhecimento, desafio, senso de separação, intemporabilidade, aventura, relevância pessoal, novidade, escapismo, cultivo intelectual. Com base, inicialmente, na relevância teórica destas dimensões referentes à experiência turística, Kim et al. (2010) dedicaram-se a relacionar o conceito de experiência turística ao construto da memória, detalhado a seguir.

\section{A EXPERIÊNCIA TURÍSTICA MEMORÁVEL (MTE)}

A memória favorável de determinada marca, produto ou serviço pode ser determinante para a tomada de decisão do consumidor. Diversos autores (Letho, O'leary, \& Morrison, 2004; Mazursky, 1989; Wirtz et al., 2003) concordam com esta colocação e propõem que a memória possui influência positiva sobre a intenção comportamental do consumidor. Diante disso, pesquisas acadêmicas referentes ao construto memória evidenciaram que determinados fatores contribuem para elevar a memorização de um evento, dentre os quais: sentimentos afetivos, avaliações cognitivas e novos eventos. Em complemento, Kim et al. (2010) afirmam que pesquisadores 
descobriram que, embora seja comum que as pessoas não recordem exatamente sobre determinados aspectos de suas experiências, como quando foram e quando voltaram, por exemplo, mesmo assim se lembram de emoções positivas e negativas sobre a viagem.

Especificamente sobre a experiência memorável no turismo, Kim et al. (2010) afirmam que se refere a uma experiência turística positiva recordada depois que o evento ocorreu. Os autores ressaltam, ainda, que o construto MTE (experiência turística memorável) representa a nova referência ou padrão a ser considerado em pesquisas de marketing turístico. Diante da relevância do conceito, Kim et al. (2010) reforçam a distinção entre os termos experiência turística memorável e experiência turística, em que no primeiro caso o turista recorda-se positivamente de uma experiência que foi capaz de proporcionar sensações positivas, enquanto no segundo a recordação não ocorre necessariamente.

O conceito de MTE ainda se apresenta recente para os estudos de marketing turístico. A literatura que aborda o conceito de forma aprofundada está em fase inicial de desenvolvimento. Diante disso, Kim et al. (2010) iniciaram um estudo de desenvolvimento e validação de uma escala capaz de mensurar e apresentar aspectos explicativos para este construto. Os autores basearamse inicialmente em conceitos abordados por estudiosos da experiência turística para a realização de levantamentos qualitativos e posteriormente testes empíricos quantitativos que fossem capazes de indicar as dimensões subjacentes ao conceito estudado.

A partir destes conceitos e de um estudo em duas fases - sendo a primeira qualitativa para verificação da adequação dos itens encontrados na literatura e a identificação de novos itens, e a segunda quantitativa para validação da escala -, Kim et al. (2010) contribuíram com a proposição de uma escala de MTE com 25 itens com elevada confiabilidade e validade, sendo capazes de explicar $75,89 \%$ da variância total do construto a partir de sete fatores: (1) hedonismo - sentimentos de prazer durante o consumo de produtos turísticos (experiências); (2) envolvimento - um envolvimento físico com a experiência de turismo; (3) novidade - a sensação psicológica de novidade 
que se resulta diante de uma nova experiência; (4) cultura local - a sensação de vivenciar a situações típicas referentes às peculiaridades culturais do destino visitado; (5) renovação - repousar-se, descansar-se, refrescar-se, renovar-se para recarregar as energias; (6) conhecimento - informações, fatos ou experiências conhecidas por um indivíduo; (7) significância sensação de vivenciar algo de grande valor ou significado.

A partir das dimensões subjacentes à experiência turística memorável (MTE) validadas empiricamente por Kim et al. (2010), pretende-se compreender se as respectivas dimensões apresentam-se válidas também junto a turistas brasileiros, a partir da tradução da escala. Para tanto, apresentam-se as hipóteses:

H1: A experiência turística memorável influencia positivamente a sensação de hedonismo.

H2: A experiência turística memorável influencia positivamente a sensação de envolvimento.

H3: A experiência turística memorável influencia positivamente a sensação de novidade.

H4: A experiência turística memorável influencia positivamente a sensação de imersão na cultura local.

H5: A experiência turística memorável influencia positivamente a sensação de renovação.

H6: A experiência turística memorável influencia positivamente a sensação de conhecimento.

H7: A experiência turística memorável influencia positivamente a sensação de significância.

PERCEPÇÃO COGNITIVA

Segundo Batey (2010), a percepção é o que acontece quando a informação sensorial é selecionada, organizada e interpretada. Em complemento, Baker e Saren (2010) argumentam que a percepção um conjunto de processos 
psicológicos, que permitem que as pessoas possam atribuir sentido e vivenciar tudo aquilo que está a sua volta a partir de processos cognitivos que selecionam, organizam e interpretam.

Peter e Olson (2006) definem como a principal função do sistema cognitivo realizar as ações de interpretar, perceber o sentido e compreender tudo aquilo que julga como aspectos significativos das experiências pessoais. Segundo os autores, isso possibilita que o sistema cognitivo crie significados simbólicos e subjetivos referentes à interpretação dos estímulos pessoais.

No âmbito do turismo, Artigas et al. (2015) afirmam que é de extrema importância que os destinos turísticos alcancem percepções cognitivas favoráveis. Baloglu e McCleary (1999) definem a percepção cognitiva como a forma pela qual a pessoa percebe todos os atributos de um destino turístico, em que os atributos percebidos incluem a paisagem e a atração, por exemplo. Em complemento, Choi, Chan e Wu (1999) afirmam que o que atrai as pessoas no ponto de vista cognitivo são as belezas das paisagens naturais e as arquitetônicas, o conforto que é gerado pelas acomodações e as qualidades particulares das atrações locais.

Anand, Holbrook e Stephens (1988) afirmam que os componentes cognitivos antecedem aos componentes afetivos e, por isso, as respostas avaliativas dos consumidores acontecem perante o seu conhecimento sobre o objeto avaliado. Baloglu e McCleary (1999) complementam que os fatores cognitivos e afetivos combinados geram uma informação global com relação à imagem do produto, seja ela negativa ou positiva. Quanto a esta avaliação no contexto do turismo, os autores conseguem mostrar em seus estudos que as avaliações de percepções cognitivas e afetivas influenciam diretamente a imagem percebida do destino. Artigas et al. (2015) argumentam que, em turismo, a percepção cognitiva se apresenta a partir de três aspectos distintos relacionados: (i) à infraestrutura do destino, (ii) ao ambiente local e (iii) ao evento e recreação. Diante disso, apresentam-se as hipóteses:

H8: A percepção cognitiva (infraestrutura) influencia positivamente a experiência turística memorável. 
H9: A percepção cognitiva (ambiente) influencia positivamente a experiência turística memorável.

H10: A percepção cognitiva (evento e recreação) influencia positivamente a experiência turística memorável.

\section{REPUTAÇÃO}

A reputação é um termo muito abordado em diversas literaturas, explorado por várias áreas de estudo, incluindo contabilidade, economia, sociologia e estratégia e marketing (Chun, 2005; Hawabhay, Abratt \& Peters, 2009).

Diante da definição do conceito de reputação, Echtner, Ritchie e Others (2003) argumentam que este construto se apresenta adequado para ser aplicado ao turismo em diferentes possibilidades de estudo. Os autores afirmam que, para se medir a imagem de um destino turístico, a reputação é um forte atributo, principalmente por se relacionar com fatores psicológicos abstratos e também estando relacionada aos atributos funcionais, físicos emensuráveis.

A reputação de destinos está fundamentada em três princípios, sendo o primeiro fundamento relacionado com a dimensão comunicacional da reputação, que envolve tudo aquilo que é dito pelas pessoas a respeito do destino com representações relacionados à cultura; o segundo fundamento está relacionado ao julgamento dos produtos e serviços usufruídos pelo turista, é uma avaliação; e o terceiro fundamento refere-se ao fato de o turista fazer uma distinção entre um destino e outro (Aula, \& Harmaakorpi, 2008; Morgan, Pritchard, \& Pride, 2011). Desempenhando um papel relevante na indústria do turismo, a reputação favorável a um destino faz com que os turistas percebam aquele local com credibilidade, enquanto, ao contrário, o destino turístico que possui reputação desfavorável perde completamente a credibilidade perante os turistas (Chen \& Dubinsky, 2003).

Diversos autores (Aula \& Harmaakorpi, 2008; Chen, \& Dubinsky, 2003; Morgan et al., 2011; Nguyen, \& Leblanc, 2001) concordam que a reputação do destino pode influenciar a percepção, a atitude e o comportamento do turista. Diante disso, apresentam-se as hipóteses: 
H11: A reputação do destino influencia positivamente a experiência turística memorável.

\section{LEALDADE AO DESTINO}

O ato de repetir uma compra, ou o fato de fazer recomendações a outras pessoas, é definido na literatura do marketing como lealdade, conceito pelo qual se observa - a partir de sua avaliação - se a estratégia de marketing obteve sucesso, segundo Flavian, Martı́nez e Polo (2001). Lealdade é observada com extrema relevância nos estudos de marketing. Souza, Gosling e Gonçalves (2013, p. 114) afirmam: "diversos autores têm ressaltado uma modificação de paradigma que estabelece lealdade como alvo principal das estratégias de marketing, e não mais a satisfação".

Os destinos turísticos podem ser considerados como produtos e os turistas podem retornar ao destino visitado novamente, ou podem recomendar o destino turístico a outros turistas ao comentar com amigos e parentes sobre a viagem realizada (Yoon, Guffey, \& Kijewski, 1993). Kozak et al. (2004) complementam que a intenção de retorno dos turistas, juntamente com a recomendação do destino turístico, constitui o construto lealdade e tem influência significativa no sucesso do destino.

Na busca pelos benefícios gerados pelo setor do turismo, há um aumento na quantidade de regiões que se apresentam como candidatas a se transformar em destinos turísticos, o que gera grande competitividade no setor (Kozak, \& Rimmington, 2000). Em concordância, Andriotis, Agiomirgianakis e Mihiotis (1993) ressaltam que, como o mercado se encontra cada vez mais saturado, para que se obtenha sucesso, os destinos devem ser orientados a realizar uma análise criteriosa das motivações turísticas e principalmente da satisfação do turista e da lealdade. Andriotis et al. (2008) acrescentam que, na busca pela competitividade, percebe-se a importância de deter conhecimento a respeito dos fatores qualidade, satisfação e lealdade.

Em complemento, diante da utilização do conceito de lealdade em pesquisas no turismo, Alexandris, Kouthouris e Meligdis (2006) argumentam 
que a satisfação em experiências turísticas contribui de forma expressiva para a lealdade ao destino (Alexandris et al., 2006).

Diante disso, pretende-se identificar se a reputação do destino e a experiência turística memorável influenciam a lealdade ao destino e, assim, apresentam-se as hipóteses:

H12: A reputação dodestino influencia positivamente a lealdade ao destino.

H13: A experiência turística memorável influencia positivamente a lealdade ao destino.

\section{MÉTODO}

O método de pesquisa utilizado é caracterizado por Gil (1999) como pesquisa conclusiva descritiva, devido ao fato de objetivar analisar relações entre variáveis e construtos a partir de hipóteses previamente estabelecidas e de pressupostos construídos por pesquisas anteriores. Este estudo é definido como quantitativo por adotar métricas numéricas para a análise do objeto de pesquisa (Gil, 1999; Gonçalves \& Meirelles, 2004). A partir das considerações de Babbie (1999), o método de coleta utilizado foi survey, o qual se apresenta como uma técnica lógica, determinística, geral, parcimoniosa e específica. Para este estudo, utilizou-se a escala tipo Likert para a mensuração padronizada dos indicadores com onze pontos de escala, que variam entre (0) "Discordo totalmente" e (10) "Concordo totalmente".

Quanto ao processo da pesquisa, inicialmente realizaram-se a tradução e a adaptação do instrumento de coleta de dados da língua original (inglês) para a língua portuguesa, a partir da técnica de tradução reversa por especialistas em tradução, registrados como tal junto aos consulados americano e britânico. Em seguida, foram realizados pré-testes a partir de entrevistas presenciais junto a 20 pessoas de perfis diversos e representantes do público-alvo da coleta de dados, o que possibilitou que fossem tomadas decisões quanto ao ajuste do questionário e à exclusão de itens redundantes, conforme sugerido por Hair, 
Black, Babin, Anderson e Tatham (2009). Seguiu-se a orientação de Malhotra (2012) para que o pré-teste fosse conduzido somente até que o momento em que se observava haver a necessidade de alterações no questionário.

A população da pesquisa é composta por turistas brasileiros que tenham como característica o fato comum de já terem vivenciado uma experiência turística memorável. Quanto à amostragem adequada, utilizouse o procedimento da amostragem bola de neve, caracterizada por Malhotra (2012) como não probabilística e iniciada a partir de respostas por um grupo inicial selecionado aleatoriamente, que, após responder, incentiva a resposta por outras pessoas. Quanto ao número de respondentes necessários, Hair et al. (2009) sugere o número mínimo de pelo menos cinco vezes o número de variáveis a serem analisadas. A partir da disponibilização do questionário na internet, por meio da ferramenta Google Docs e do incentivo ao compartilhamento por e-mail e Facebook, obteve-se o número total de 664 respondentes, o que representa a proporção de 15,4 vezes o número de 43 variáveis analisadas, portanto mais que o triplo da proporção sugerida por Hair et al. (2009).

O procedimento para a validação do modelo teórico deste estudo, a partir da amostra coletada, foi realizado por meio de técnica de modelagem de equações estruturais (SEM), que se apresenta como uma extensão de métodos da estatística multivariada, especificamente da regressão múltipla e da análise fatorial. Segundo Bagozzi e Yi (2012), a modelagem de equações estruturais (SEM) envolve "procedimentos estatísticos para testes de hipóteses causais, preditivas, funcionais e de mensuração". Gosling e Gonçalves (2003) afirmam que a modelagem de equações estruturais é uma abordagem estatística adequada para se "testar hipóteses a respeito de relações entre variáveis latentes observadas".

A técnica PLS-SEM (Partial Least Squares Structural Equation Modeling) é adequada para otimização de predições, servindo comoabordagem exploratória de análise na construção de teorias Hair, Hult, Ringle e Sarstedt (2013).

Para a modelagem de equações estruturais, seguiu-se a orientação de Hair et al. (2009) para a adoção de seis estágios: Definir construtos individuais (1); Desenvolver o modelo de mensuração geral (2); Planejar um estudo para produzir resultados empíricos (3); Avaliar a validade do modelo de mensuração (4); Especificar o modelo estrutural (5); Avaliar a validade do modelo estrutural (6). 


\section{ANÁLISE DOS RESULTADOS}

A amostra é composta por respondentes de todas as 27 unidades federativas do Brasil, de todas as cinco regiões do país. Cerca de 70\% (ou 401) possui até 34 anos. A proporção de 95\% (ou 548) possui ensino superior ao menos incompleto, sendo que 59,6\% (ou 344) possui ensino superior completo. Quanto à renda familiar mensal, 74\% (ou 429) possui renda acima de $R \$ 2.565,00$, sendo que $55 \%$ (ou 4316) possui renda acima de $R \$ 4.077,00$. No que se refere ao destino turístico relatado pelos respondentes como local da experiência turística memorável vivenciada, 56\% (ou 323) indicou destinos nacionais e 44\% (ou 254) indicou destinos internacionais. Quanto ao motivo da viagem, 60\% (ou 345) alegou ter realizado viagem por prazer. 33\% (ou 191) informou que o orçamento da viagem foi acima de $R \$ 4.000,00$, sendo que $41 \%$ (ou 237) informou ter se hospedado em hotéis até quatro estrelas.

Para a correta análise dos resultados, inicialmente, realizou-se o exame dos dados. O primeiro passo foi a análise univariada - a partir da identificação dos valores extremos (> 4 e < -4) dos escores padronizados $z$; e multivariada - a partir do método de Mahalanobis e a análise dos valores resultantes (> 3) da fórmula $D^{2} / d f$.

Observou-se que 87 casos se apresentaram como outliers, optandose pela exclusão dos mesmos. Dessa forma, chegou-se a um número de 577 observações a serem analisadas nos procedimentos subsequentes. Em seguida, foi realizado o teste de Kolmogorov-Smirnov (K-S), em que se constatou a não normalidade dos dados. Diante da não normalidade, Pasquali (2005) afirma não ser um problema que afete gravemente a análise fatorial. No caso desta pesquisa, ratifica a decisão pelo método PLS. Isso porque é uma técnica de estimação não paramétrica, que não exige apresentação de normalidade na distribuição dos dados (Hair et al., 2013).

Realizou-se, também, a análise de linearidade, a qual ocorre por meio de correlações par a par. Este estudo considerou a orientação de Hair et al. (2009) para utilizar o teste não paramétrico da correlação de Spearman. A partir desta técnica, considera-se o fato de que as correlações apresentam indicativos de dados lineares ao serem todas significativas ao nível de $1 \%$ 
$(<0,01)$ e ao nível de 5\% (<0,05). Em linhas gerais, observa-se que 95\% das correlações foram consideradas significativas ao nível de $1 \%(<0,01)$, 0 que indica a linearidade dos dados. Quanto à análise dos dados ausentes, esta não se fez necessária, pois a coleta dos dados se deu por meio de um questionário organizado na ferramenta Google Docs, em que se criou a obrigatoriedade do preenchimento de todas as respostas.

A análise fatorial exploratória aplicada neste estudo considerou o objetivo de compreender a relação entre as variáveis. Para tanto, aplicou-se a análise fatorial $R$. Para o resumo e a redução dos dados, aplicou-se o método de extração de fatores de componentes principais (PCA), sugerido por Hair et al. (2009). Quanto ao método rotacional, optou-se pelo método oblíquo, em que se considerou a técnica de OBLIMIN, por se enquadrar no método de rotação oblíqua, ressaltado por Hair et al. (2009, p.119), porque "permite fatores correlacionadosemvezdemanterindependênciaentreosfatoresrotacionados". Baseou-se em Hair et al. (2009) para que a análise fatorial exploratória fosse aplicada em etapas: inicialmente consideraram-se as dimensões subjacentes à MTE (Hedonismo, Novidade, Renovação, Envolvimento, Cultura Local e Conhecimento); em sequência as variáveis latentes exógenas (Reputação, Percepção Cognitiva Infraestrutura, Percepção Cognitiva Ambiente, Percepção Cognitiva Evento e Recreação); e, posteriormente, a variável latente endógena da Lealdade. Na análise fatorial exploratória das dimensões subjacentes à MTE o critério de Kaiser-Meyer-Olking (KMO) - o qual avalia a adequação da análise fatorial a partir do parâmetro entre 0,5 e 1,0 - evidenciou a adequação ao apresentar o valor de 0,844. Além disso, o teste de esfericidade de Barlett (TEB) - o qual avalia a significância geral de todas as correlações em uma matriz de correlação a partir do parâmetro < 1\% - evidenciou-se adequado ao apresentar o valor de 0,000. Na análise das variáveis latentes exógenas e na análise da variável latente endógena da Lealdade, os valores encontrados para KMO foram, respectivamente, 0,858 e 0,658. Ressalta-se, ainda, que nos dois casos o teste de esfericidade de Barlett evidenciou a significância das relações ao nível de $1 \%$ a partir do valor de 0,000.

Hair et al. (2009) orientam que, além da realização dos testes, para que a adequação da utilização da técnica de AFE seja verificada, é imprescindível 
que a qualidade dos resultados encontrados seja constatada. Para tanto, recomenda-se a utilização da variância explicada, uma medida que indica a proporção pela qual as variáveis são capazes de explicar o construto ao qual se referem (Hair et al., 2009). Malhotra (2012) e Hair et al. (2009) recomendam que seja superior a $50 \%$. Na análise referente às variáveis latentes subjacentes à TEM, o valor encontrado para a variância explicada foi de 63,411\% para 5 componentes; na análise das variáveis latentes exógenas o valor foi de $72.684 \%$ para 4 componentes; e na variável latente endógena foi de $64,896 \%$ para um componente.

Para que fosse possível chegar ao resultado observado na Tabela 1, fez-se necessário optar pela exclusão de variáveis que apresentaram cargas inferiores a 0,4, conforme recomendado por Hair et al. (2009). Ressalta-se que para a exclusão de cada variável considerou-se, além dos resultados apresentados na análise, o embasamento teórico de cada construto e variável. Quanto à comunalidade $\left(\mathrm{h}^{2}\right)$, observa-se que todas as variáveis apresentaram valor superior ao parâmetro de 0,4 recomendado (Hair et al., 2009).

As variáveis excluídas durante a análise fatorial dos construtos exógenos foram cinco. Além da exclusão da variável CONHECI1 (Tive a oportunidade para explorar o local visitado) e PCINFRA2 (As instalações neste lugar são muito diversificadas (exemplo: muitos restaurantes, praças, etc.)), é possível observar que a dimensão significância (SIGNIFI) foi excluída por completo da análise junto com as variáveis que a compunham. A partir da análise fatorial foi possível observar, também, a aderência das variáveis de mensuração CONHECI2 e CONHECI3 a todas as variáveis de mensuração da dimensão cultura local (CULTLOC) em um mesmo fator.

Em sequência, iniciou-se a avaliação do modelo de mensuração, a fim de avaliar a validade e a confiabilidade do modelo (Hair et al., 2013). Para a análise de confiabilidade, seguiu-se a orientação de Henseler, Ringle e Sinkovics (2009), em que se considera que a confiabilidade composta é mais adequada ao modelo PLS-SEM do que o Alfa de Cronbach. Diante disso, observa-se que a confiabilidade das variáveis latentes é evidenciada a partir da consideração de que todos os fatores apresentaram valores de 

confiabilidade composta acima de 0,800 (Tabela 1). Além disso, os valores acima de 0,5 para a medida da variância média extraída (AVE) evidenciam a validade convergente dos construtos (Henseler et al., 2009).

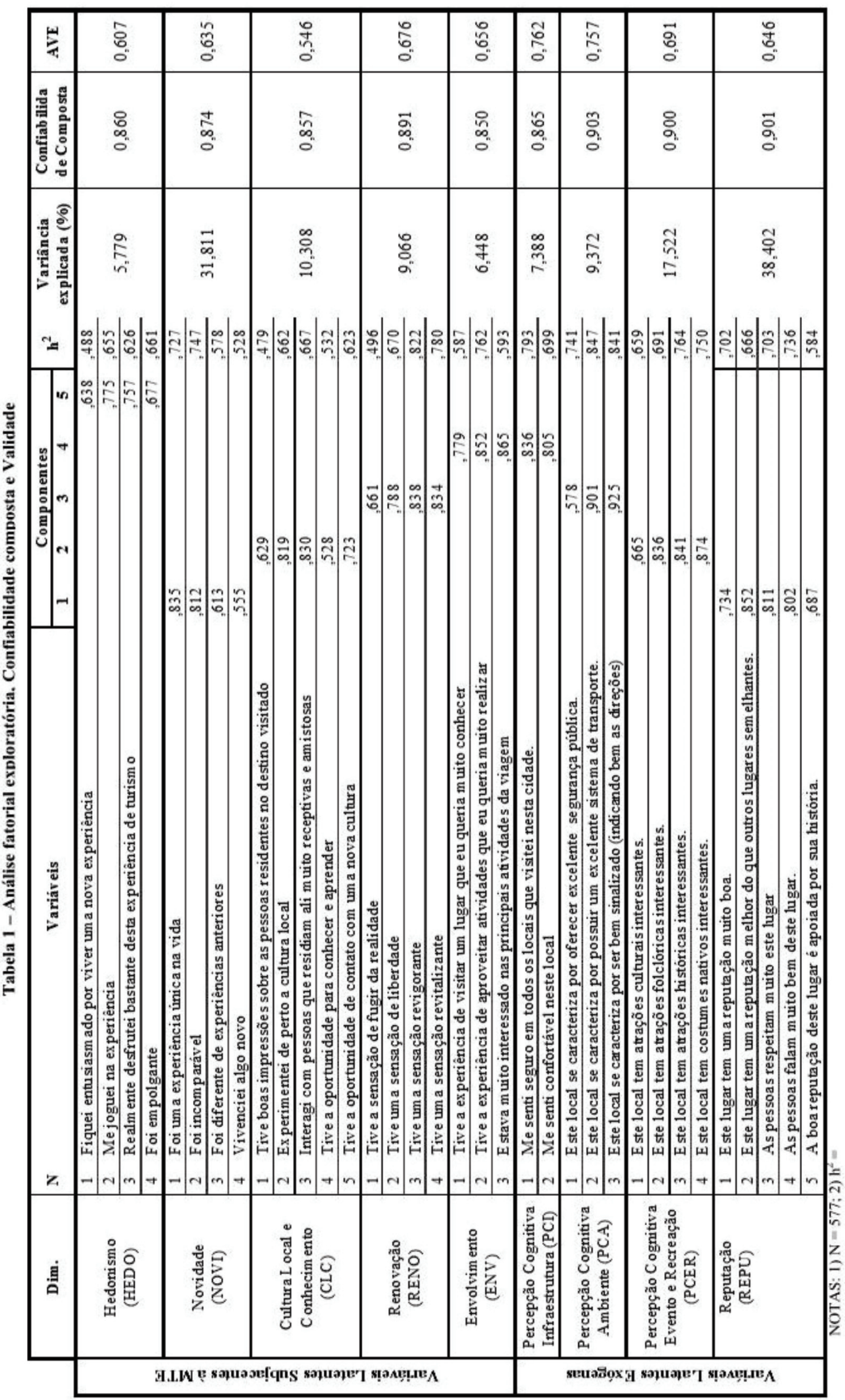


A validade discriminante dos construtos é evidenciada a partir do critério de Fornell-Larcker (Tabela 2) e do teste de cargas cruzadas, em que se observou que o valor das cargas cruzadas (indicadores que formam o construto cruzado com o construto), em todos os casos, apresentou-se superior ao das outras cargas.

Tabela 2 - Análise de validade discriminante pelo critério de Fornell-Larcker

\begin{tabular}{|c|c|c|c|c|c|c|c|c|c|c|}
\hline & CLC & ENV & HEDO & LEAL & NOVI & PCA & PCER & PCI & RENO & REPU \\
\hline CLC & 0,739 & & & & & & & & & \\
\hline ENV & 0,406 & 0,810 & & & & & & & & \\
\hline HEDO & 0,316 & 0,438 & 0,779 & & & & & & & \\
\hline LEAL & 0,336 & 0,417 & 0,405 & 0,803 & & & & & & \\
\hline NOVI & 0,336 & 0,421 & 0,565 & 0,392 & 0,797 & & & & & \\
\hline PCA & 0,300 & 0,293 & 0,162 & 0,214 & 0,191 & 0,870 & & & & \\
\hline PCER & 0,509 & 0,311 & 0,182 & 0,264 & 0,239 & 0,372 & 0,831 & & & \\
\hline PCI & 0,331 & 0,335 & 0,347 & 0,447 & 0,334 & 0,472 & 0,253 & 0,873 & & \\
\hline RENO & 0,337 & 0,338 & 0,392 & 0,377 & 0,398 & 0,174 & 0,149 & 0,407 & 0,822 & \\
\hline REPU & 0,300 & 0,321 & 0,239 & 0,428 & 0,279 & 0,504 & 0,235 & 0,505 & 0,299 & 0,804 \\
\hline
\end{tabular}

Fonte: Elaborado pelos autores.

Além disso, é possível observar, a partir da Figura 1, com o modelo de pesquisa ajustado e os resultados finais que o $R^{2}$ ajustado da dimensão lealdade ao destino apresenta o valor de 0,399. Destaca-se, ainda, que a dimensão subjacente à experiência turística memorável que apresentou maior coeficiente de determinação foi a dimensão novidade a partir do valor $\mathrm{R}^{2}$ ajustado de 0,593.

A partir dos coeficientes de caminho apresentados na Figura 1, observase que todas as cinco dimensões avaliadas pelo modelo estrutural como subjacentes à experiência turística memorável (hedonismo, envolvimento, novidade, cultura local e conhecimento, renovação) apresentaram significância estatística ao nível de 1\%. Diante disso, pode-se afirmar que o teste empírico realizado validou as hipóteses $\mathrm{H} 1, \mathrm{H} 2, \mathrm{H} 3, \mathrm{H} 4$ e $\mathrm{H} 6$, além de $\mathrm{H} 5$, as quais se referiam, respectivamente, à relação subjacente à experiência turística memorável (MTE). As hipóteses $\mathrm{H} 4$ e $\mathrm{H} 6$ especificamente foram validadas a partir da validação da relação da dimensão MTE perante a dimensão integrada cultura local e conhecimento. Das dimensões subjacentes à MTE somente não foi validada a dimensão significância.

Considerou-seaargumentação deArtigasetal.(2015) para quea percepção cognitiva fosse mensurada a partir das três dimensões infraestrutura, ambiente e evento e recreação, as quais se referiam respectivamente às 
hipóteses $\mathrm{H}_{8^{\prime}} \mathrm{H}_{9}$ e $\mathrm{H}_{10}$. As hipóteses $\mathrm{H} 8 \mathrm{e} \mathrm{H} 10$, referentes à relação antecedente de influência positiva, respectivamente, das dimensões percepção cognitiva infraestrutura e percepção cognitiva evento e recreação perante a experiência turística memorável (MTE), foram validadas. A hipótese $H 9$, referente à relação antecedente da dimensão percepção cognitiva ambiente perante a TEM, não foi validada pelo teste empírico.

Ashipóteses $\mathrm{H} 11$ e H12 referem-seà influência positiva da dimensão reputação, respectivamente, nas dimensões MTE e lealdade ao destino. Ambas foram validadas. Por fim, a hipótese $H 13$, referente à influência positiva da dimensão MTE perante a lealdade ao destino, também apresentou significância estatística ao nível de $1 \%$ e, portanto, foi validada pelo teste empírico realizado.

\section{CONSIDERAÇÕES FINAIS}

O principal objetivo deste estudo foi mensurar um modelo capaz de apontar as relações entre as dimensões subjacentes da experiência turística memorável, percepção cognitiva, reputação e lealdade ao destino junto aos turistas brasileiros. Diante disso, realizou-se pesquisa survey em que foram coletadas informações de 664 respondentes das 27 unidades federativas em todas as regiões do Brasil. A partir da análise fatorial exploratória foi possível identificar que, para a melhor adequação dos dados, foi necessário realizar a exclusão de cinco itens, sendo um referente à dimensão conhecimento, um referente à dimensão percepção cognitiva infraestrutura e os demais eram referentes a todos as variáveis que compunham a dimensão significância. A análise fatorial exploratória também evidenciou a possibilidade de fusão das dimensões cultura local e conhecimento.

A partir dos resultados, observou-se que os cinco construtos analisados como dimensões subjacentes à MTE (hedonismo, envolvimento, novidade, cultura local e conhecimento, renovação) a partir da modelagem de equação estrutural apresentaramconfiabilidade, validadeconvergenteediscriminante. Além disso, destaca-se que a dimensão que apresentou maior coeficiente de determinação ( $R^{2}$ ajustado) a partir da influência da MTE foi a dimensão novidade, a qual apresentou 59,3\% de determinação. 
Ressalta-se que os resultados dos testes empíricos realizados neste estudo evidenciam a influência positiva das dimensões reputação, percepção cognitiva infraestrutura e percepção cognitiva evento e recreação diretamente na dimensão experiência turística memorável. Tal fato indica que quanto maior a reputação do destino, bem como quanto maior a percepção cognitiva do turista perante ao local visitado, mais memorável tende a ser a experiência turística vivenciada. Em complemento, tem-se que quanto mais memorável a experiência turística, bem como quanto mais elevada a reputação do destino, maior tenderá a ser a lealdade ao destino.

Em âmbito gerencial, este estudo promove contribuições ao expor direcionamentos específicos quanto aos aspectos principais a serem aprimorados por organizações turísticas que objetivem tornar mais memorável a experiência turística vivenciada pelo turista, bem como potencializar a lealdade ao destino. Os aspectos principais a serem desenvolvidos pelas organizações turísticas são: reputação do destino; percepção cognitiva infraestrutura e percepção cognitiva evento e recreação. Além disso, este estudo indica para gestores de organizações turísticas que desenvolverações que influenciem sensações de hedonismo, envolvimento, novidade, cultura local e conhecimento e renovação junto aos turistas brasileiros tendem a potencializar a recordação da experiência turística vivenciada e, assim, aumentar a possibilidade de lealdade ao destino.

No âmbito acadêmico, esta pesquisa contribuiu para a expansão e o aprofundamento dos estudos das relações entre as dimensões subjacentes da experiência turística memorável, percepção cognitiva, reputação e lealdade ao destino. Em complemento, observa-se que a transposição da escala de MTE - desenvolvida por Kim et al. (2010) - para a aplicação junto a turistas brasileiros apresenta-se também como uma contribuição relevante para a academia. Outra considerável contribuição deste estudo é a validação empírica de que a experiência turística memorável está diretamente relacionada às sensações de hedonismo, envolvimento, novidade, cultura local e conhecimento, renovação. A validação empírica deste estudo apresenta-se em confluência à argumentação de Lipovetsky e Machado (2007) referente 
à expectativa do consumidor contemporâneo pelo consumo de experiências capazes de estabelecer laços emocionais e sentimentais.

Pode-se considerar relevante a contribuição acadêmica proporcionada por este estudo ao evidenciar a influência positiva da dimensão reputação perante a experiência turística memorável. Acrescenta-se, ainda, a contribuição evidenciada pela constatação da influência positiva da percepção cognitiva (infraestrutura, evento e recreação) perante a MTE.

Quanto às limitações do estudo, ressalta-se que o método quantitativo se apresenta como mera simplificação das reais relações existentes, não sendo capaz de expressá-las por completo (Box \& Draper, 1987). Além disso, é relevante reforçar que aspectos como a amostra por conveniência e a coleta transversal podem influenciar os dados, bem como limitam a possibilidade de generalização dos resultados.

Como sugestão para estudos futuros, propõem-se: a utilização de amostra mais representativa e ampla; a utilização de variáveis não métricas, tais como, gênero, idade, região, estado, frequência de viagens realizadas, como moderadoras das relações estudadas, para identificar se estas variáveis apresentam influência significativa nos resultados; a introdução de uma fase qualitativa capaz de compreender, por meio de métodos como grupos de foco e entrevistas semiestruturadas; a percepção de turistas e gestores de organizações turísticas quanto aos principais aspectos a serem considerados na escala estudada; o emprego de novos construtos como variáveis dependentes na modelagem de equações estruturais para identificar novas relações entre os fatores; a utilização de outras técnicas de análise, como CB-SEM, para amostras maiores.

\section{REFERÊNCIAS}

Alexandris, K., Kouthouris, C., \& Meligdis, A. (2006). Increasing customers' loyalty in a skiing resort: The contribution of place attachment and service quality. International journal of contemporary hospitality management, 18(5), 414-425.

Anand, P., Holbrook, M. B., \& Stephens, D. (1988). The formation of affective judgments: The cognitive-affective model versus the independence hypothesis. Journal of Consumer Research, 15(3), 386-391. 
Andriotis, K., Agiomirgianakis, G., \& Mihiotis, A. (2008). Measuring tourist satisfaction: A factor-cluster segmentation approach. Journal of Vacation Marketing, 14(3), 221-235.

Artigas, E. M., Vilches-Montero, S., \& Yrigoyen, C. C. (2015). Antecedents of tourism destination reputation: The mediating role of familiarity. Journal of Retailing and Consumer Services, 26, 147-152.

Aula, P., \& Harmaakorpi, V. (2008). An innovative milieu-a view on regional reputation building: case study of the Lahti urban region. Regional Studies,42(4), 523-538.

Babbie, E. (1999) Métodos de pesquisas de survey. Ed. UFMG.

Bagozzi, R. P., \& Yi, Y. (2012). Specification, evaluation, and interpretation of structural equation models. Journal of the academy of marketing science,40(1), 8-34.

Baker, M. J., \& Saren, M. (2010) Marketing theory: a student text. Sage.

Baloglu, S., \& McCleary, K. W. (1999). A model of destination image formation. Annals of tourism research, 26(4), 868-897.

Batey, M. (2010) O significado da marca: como as marcas ganham vida finamente dos consumidores. Rio de Janeiro: Best Business.

Beni, M. C. (2002) O profissional do turismo na sociedade pós-industrial. Turismo: investigação e crítica. São Paulo: Contexto.

Beni, M. C. (2003) Análise estrutural do turismo. Senac.

Box, G. E., \& Draper, N. R. (1987) Empirical model-building and response surfaces. Wiley New York, v. 424.

Chen, Z., \& Dubinsky, A. J. (2003). A conceptual model of perceived customer value in e-commerce: A preliminary investigation. Psychology \& Marketing, 20(4), 323-347.

Choi, W. M., Chan, A., \& Wu, J. (1999). A qualitative and quantitative assessment of Hong Kong's image as a tourist destination. Tourism management, 20(3), 361-365.

Christou, E. (2003). Guest loyalty likelihood in relation to hotels' corporate image and reputation: a study of three countries in Europe. Journal of Hospitality \& Leisure Marketing, 10(3-4), 85-99.

Chun, R. (2005). Corporate reputation: Meaning and measurement.International Journal of Management Reviews, 7(2), 91-109.

Echtner, C. M., Ritchie, J. B., \& Others. (2003) The meaning and measurement of destination image. Journal of tourism studies, 14(1), 37-48. 
Flavian, C., Martí nez, E., \& Polo, Y. (2001). Loyalty to grocery stores in the Spanish market of the 1990s. Journal of Retailing and Consumer Services,8(2), 85-93.

Gil, A. C. (1999) Pesquisa social: métodos e técnicas (Vol 5). São Paulo: Atlas.

Gonçalves, C. A., \& Meirelles, A. M. (2004) Projetos e relatórios de pesquisa em administração. Atlas, 2004.

Gosling, M., \& Gonçalves, C. A. (2003). Modelagem por Equações Estruturais: conceitos e aplicações. Revista de Administração FACES Journal, 2(2).

Hair, J. F., Black, W. C., Babin, B. J., Anderson, R. E., \& Tatham, R. L. (2009) Análise multivariada de dados. Bookman.

Hair Jr. J. F., Hult, G. T. M., Ringle, C., \& Sarstedt, M. (2013) A primer on partial least squares structural equation modeling (PLS-SEM). Sage Publications.

Hawabhay, B. B., Abratt, R., \& Peters, M. (2009). The role of corporate communications in developing a corporate brand image and reputation in Mauritius. Corporate reputation review, 12(1), 3-20.

Henseler, J., Ringle, C. M., \& Sinkovics, R. R. (2009). The use of partial least squares path modeling in international marketing. Advances in international marketing, 20(1), 277-319.

Holbrook, M. B., \& Hirschman, E. C. (1982). The experiential aspects of consumption: Consumer fantasies, feelings, and fun. Journal of consumer research, 9(2), 132-140.

Jensen, R. (1999) The dream society: how the coming shift from information to imagination will transform your business. McGraw-Hill New York.

Kim, J. H., Ritchie, J. B., \& McCormick, B. (2010). Development of a scale to measure memorable tourism experiences. Journal of Travel Research.

Kozak, M., Bigné, E., Andreu, L., \& Others (2004). Satisfaction and destination loyalty: A comparison between non-repeat and repeat tourists. Journal of Quality Assurance in Hospitality \& Tourism, 5(1), 43-59.

Kozak, M., \& Rimmington, M. (2000) Tourist satisfaction with Mallorca, Spain, as an offseason holiday destination. Journal of travel research, 38(3), 260-269.

Lehto, X. Y., O'leary, J. T., \& Morrison, A. M. (2004) The effect of prior experience on vacation behavior. Annals of Tourism Research, 31(4), 801-818.

Lipovetsky, G.; Machado, M. L. (2007) A felicidade paradoxal: ensaio sobre a sociedade de hiperconsumo. 
Malhotra, N. K. (2012) Pesquisa de marketing: uma orientação aplicada. Bookman.

Mazursky, D. (1989) Past experience and future tourism decisions. Annals of Tourism Research, 16(3), 333-344.

Mehmetoglu, M., \& Engen, M. (2011) Pine and Gilmore's concept of experience economy and its dimensions: An empirical examination in tourism. Journal of Quality Assurance in Hospitality and Tourism, 12(4), 237-255, 2011.

Ministério do Turismo. (2012) Recuperado de http://www.turismo.gov.br/.

Morgan, N., Pritchard, A., \& Pride, R. (2011) Destination brands: Managing place reputation. Routledge.

Nguyen, N., \& Leblanc, G. (2001) Corporate image and corporate reputation in customers' retention decisions in services. Journal of retailing and Consumer Services, 8(4), 227-236.

Oh, H., Fiore; A. M., \& Jeoung, M. (2007) Measuring experience economy concepts: Tourism applications. Journal of travel research, 46(2), 119-132.

Oliani, L. G. N., Rossi, G. B., \& Gervasoni, V. C. (2011) What are the attractiveness factors that influence the choice of a tourist destination-a study of Brazilian tourist consumer. Chinese Business Review, 10(4), 286-293.

Ooi, C-S. (2005) A theory of tourism experiences: The management of attention. Experiencescapes: Tourism, Culture and Economy, 51-68.

Pasquali, L. (2005) Análise fatorial para pesquisadores. LabPAM.

Peter, J. P., \& Olson, J. C. (2006) Comportamento do consumidor e estratégia de marketing. McGraw Hill Brasil.

Pike, S. D. (2004) Destination brand positioning slogans-towards the development of a set of accountability criteria. Acta Turistica, 16(2), 102-124.

Pine, B. J., \& Gilmore, J. H., \& Others. (1998) Welcome to the experience economy. Harvard business review, 97-105.

Pine, B. J., \& Gilmore, J. (1999) O espetáculo dos negócios. Tradução: Maria José Cyhlar Monteiro. Rio de Janeiro: Campus.

Richards, G., \& Others. (2001) The experience industry and the creation of attractions. Cultural attractions and European tourism, 55-69. 
Schmitt, B. H. (2002) Marketing experimental-Exame. NBL Editora.

Souza, B. B. P., Gosling, M., \& Gonçalves, C. A. (2013) Mensuração do Mix de Marketing de Serviços, da Satisfação e da Lealdade em Clientes de um Banco de Varejo. Revista Brasileira de Marketing, 12(2), 108-132.

Tarssanen, S.; Kylänen, M. (2007) A theoretical model for producing experiences- a touristic perspective. Articles on experiences, 2, 134-154.

Tonini, H. (2009) Economia da experiência: o consumo de emoções na Região Uva e Vinho/RS. RBTur, 3(1), 90-107.

Unwto. (2014) World Tourism Organization. Recuperado de http://www.2unwto.org/.

Wirtz, D., Kruger, J., Scollon, C. N., \& Diener, E. (2003) What to do on spring break? The role of predicted, on-line, and remembered experience in future choice. Psychological Science, 14(5), 520-524.

Yoon, E., Guffey, H. J., \& Kijewski, V. (1993) The effects of information and company reputation on intentions to buy a business service. Journal of Business Research, 27(3), 215-228. 